\title{
Prevalence of Childhood Asthma in Korea: International Study of Asthma and Allergies in Childhood
}

\author{
Sang-II Lee* \\ Department of Pediatrics, Samsung Medical Center, Sungkyunkwan University School of Medicine, Seoul, Korea
}

This is an Open Access article distributed under the terms of the Creative Commons Attribution Non-Commercial License (http://creativecommons.org/licenses/by-nc/3.0/) which permits
unrestricted non-commercial use, distribution, and reproduction in any medium, provided the original work is properly cited.

Childhood asthma is a major concern because it leads to more hospital visits and a heavy economic burden. Proper management and prevention strategies for childhood asthma must be based on correct evaluation of prevalence and risk factors for its development. In Korea, nationwide studies were conducted in 1995 and 2000 on students from 68 elementary schools (age, 6-12 years) and junior high schools (age, 12-15 years) by the Korean Academy of Pediatric Allergy and Respiratory Diseases. We used the Korean version of the International Study of Asthma and Allergies in Childhood (ISAAC) written and video questionnaires at the same schools during the same period (October-November). The prevalence of asthma in junior high school children seemed to increase over 5 years. However, in elementary school children, the prevalence of asthma symptoms decreased, although the prevalence of 'diagnosis of asthma, ever' and 'treatment of asthma, last 12 months' increased. In addition, it was found that various factors, such as obesity, passive smoking, dietary habits, raising pets at home, and fever/antibiotic use during infancy were associated with childhood asthma. When prevalence of asthma in Korea was compared with that in different regions, the prevalence changes in the 6-7 years age group did not seem to be consistent between regions, whereas similar trends were observed among children aged 13-14 years. To conduct another epidemiological study to evaluate the time trend over time, a third nationwide survey is planned in 2010, and we anticipate ISAAC Phase 3 will explore recent changes in the prevalence of childhood asthma and assess its risk factors in Korean children. On the basis of accurate data on the current status of childhood asthma in 2010, we will be able to establish proper management strategies.

Key Words: Asthma; child; Korea

\section{INTRODUCTION}

Childhood asthma is a major concern because it leads to more hospital visits and a heavy economic burden. The pathogenesis has not been clearly elucidated, but various factors such as economic development, ${ }^{1}$ exposure to tobacco smoke, ${ }^{2}$ exposure to air pollution, ${ }^{3-6}$ infection, ${ }^{7}$ climate, ${ }^{8}$ diet,${ }^{9,10}$ obesity, ${ }^{11-13}$ antibiotic use, ${ }^{14}$ and exposure to allergens ${ }^{15,16}$ are known to be associated with childhood asthma. Establishment of proper management and prevention strategies for childhood asthma must be based on correct evaluation of prevalence and risk factors for its development. In addition, there is widespread concern that the prevalence of childhood asthma is still increasing in many countries. Under the consensus to investigate childhood asthma, allergic rhinoconjunctivitis, and atopic eczema at the population level, the International Study of Asthma and Allergies in Childhood (ISAAC) was designed and first conducted in $1995 .{ }^{17-19}$ The worldwide research program has compared demographic and clinical characteristics in a standardized way in different populations; therefore, new information on allergic diseases in chil- dren can be collected. In Korea, the Korean Academy of Pediatric Allergy and Respiratory Diseases (KAPARD) has participated in the nationwide survey of ISAAC two times over a 5-year period. Here, the prevalence of childhood asthma and its risk factors in Korea are described and compared with those from other countries.

\section{PREVALENCE AND RISK FACTORS FOR ASTHMA IN KOREAN CHILDREN}

In 1995 and 2000, nationwide studies were conducted on students from 68 elementary schools (age, 6-12 years) and junior high schools (age, 12-15 years) located in Seoul and the eight major cities in Korea (Ansan, Ulsan, Suwon, Jeju, Changwon,

Correspondence to: Sang-II Lee, MD, PhD, Department of Pediatrics, Samsung Medical Center, 50 Irwon-dong, Gangnam-gu, Seoul 135-710, Korea. Tel: +82-2-3410-3521; Fax: +82-2-3410-0043; E-mail: childslee@skku.edu Received: February 27, 2010; Accepted: February 27, 2010

- There are no financial or other issues that might lead to conflict of interest. 
Cheongju, Chooncheon and Jeonju) by the same investigators (members of the Epidemiologic Study Committee of the KAPARD). We used the Korean version of ISAAC written and video questionnaires at the same schools during the same period (October to November). Parents were asked to complete the questionnaires instead of their elementary school students. Junior high school students themselves answered the questions and also completed answers to a video questionnaire. Surveyed schools comprised 10 elementary schools and 10 junior high schools in Seoul as well as 24 elementary schools and 24 junior high schools in the aforementioned eight cities. The response rate was $94.8 \%$ in 1995 and $96.4 \%$ in 2000 . Surveyed subjects were 25,117 elementary school students and 14,946 junior high school students in 1995, and they were 27,831 elementary school students and 15,214 junior high school students in 2000. ${ }^{20-23}$

The prevalence of "wheeze ever" was $17.0 \%$ in 1995 and decreased to $13.0 \%$ in 2000 for elementary school students, whereas it was $13.9 \%$ and $12.8 \%$ for junior high school students in 1995 and in 2000, respectively. The prevalence of "wheeze, last 12 months" was $9.5 \%$ in 1995 and decreased to $4.9 \%$ in 2000 for elementary school students, whereas it was $8.5 \%$ in 1995 and 9.3\% in 2000 for junior high school students, with no significant difference in prevalence (Figs. 1 and 2). The prevalence of "diagnosis of asthma, ever" was $7.7 \%$ in 1995 and increased to $9.1 \%$ in 2000 for elementary school students. In addition, it was $2.7 \%$ in 1995 and increased to $5.3 \%$ in 2000 for junior high school students, and the difference was statistically significant (Figs. 1 and 2). There was no change in the prevalence of "treatment of asthma, last 12 months" with $3.2 \%$ and 3.3\% in 1995 and 2000, respectively, for elementary school students, whereas for junior high school students it significantly increased from 1.0\% in 1995 to $1.8 \%$ in 2000 (Figs. 1 and 2).

The results of the video questionnaire survey in junior high school students were as follows. The prevalence of "wheeze,

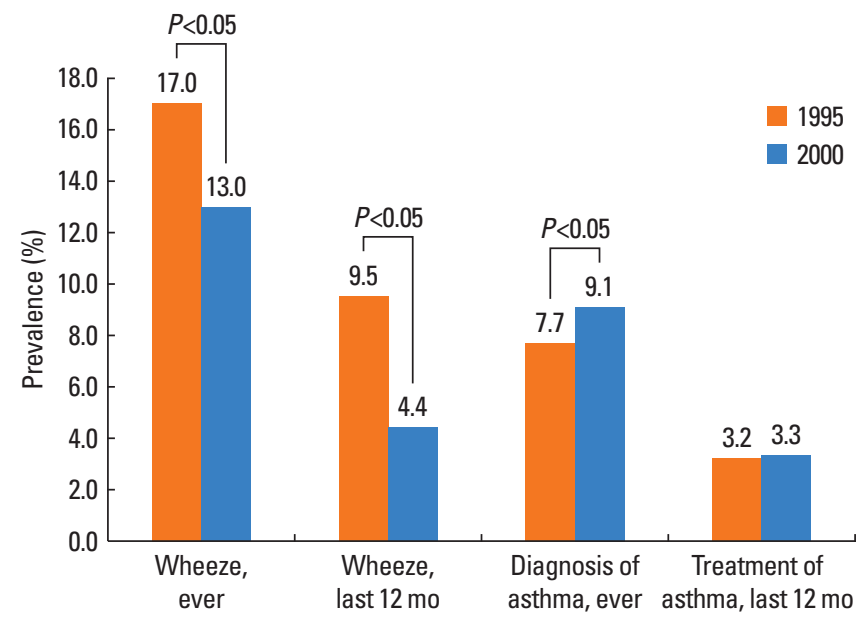

Fig. 1. Prevalence of asthma by the written questionnaire survey in elementary school children (6-12 years). ever" was $6.7 \%$ in 1995 and increased to $8.7 \%$ in 2000 . The prevalence of "wheeze, 12 months" was 3.9\% in 1995 and increased to $5.5 \%$ in 2000 . The prevalence of "exercise-induced wheeze, ever" was $10.0 \%$ in 1995 and increased to $16.8 \%$ in 2000 . The prevalence of "exercise-induced wheeze, last 12 months" was $6.6 \%$ in 1995 and increased to $11.7 \%$ in 2000 . In addition, the prevalence of "nocturnal wheeze and cough" and "severe wheeze" increased in 2000, as compared to that in 1995 (Table 1).

Taken together, the prevalence of "diagnosis of asthma, ever" and "treatment of asthma, last 12 months" in junior high school students increased over 5 years, and these data are consistent with increased prevalence of asthma symptoms by video questionnaire. The prevalence of "wheeze, last 12 months" showed a similar trend, although this was not statistically significant. When the written questionnaires were completed by students themselves in this age group, the decreased prevalence of "wheeze, ever" might not be reliable data, because the students may not have remembered the wheezing episode correctly. In contrast, for elementary school children, the prevalence of asthma symptoms significantly decreased in 2000 , as compared to those in 1995, while that of diagnosis/treatment of asthma increased. There is no good explanation for this discrepancy, but it might reflect increased awareness of childhood asthma and subsequent successful management. There is still a possibility of recall bias on the part of parents who answered the questionnaire for their elementary school children.

In the second survey in 2000 , the association between potential risk factors and development of childhood asthma was also investigated. In elementary school children, a significant positive association between high body mass index (BMI) and previous 12 months prevalence of wheeze was found in boys [adjusted odds ratio (aOR) 1.610; 95\% confidence interval (CI), 1.274-2.033], but not in girls. ${ }^{13}$ Frequent intake of fresh seafood, fresh fruits, and vegetables was associated with reduced preva-

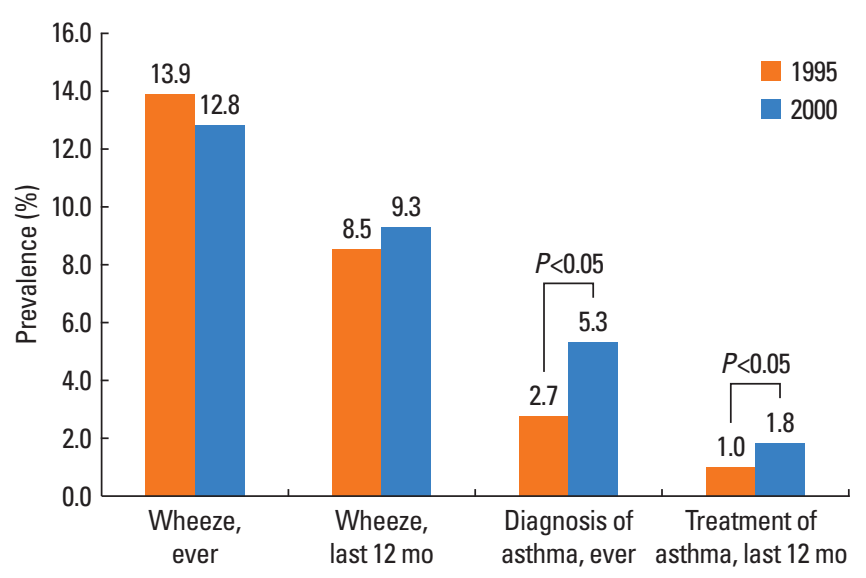

Fig. 2. Prevalence of asthma by the written questionnaire survey in junior high school children (12-15 years). 
Table 1. Prevalence of asthma symptoms by the video questionnaire survey in junior high school children

\begin{tabular}{lcc}
\hline & 1995 & 2000 \\
\hline Wheeze at rest & & \\
$\quad$ Ever & 6.7 & $8.7^{*}$ \\
$\quad$ Last 12 mo & 3.9 & $5.5^{*}$ \\
Exercise-induced wheeze & & \\
$\quad$ Ever & 10.0 & $16.8^{*}$ \\
$\quad$ Last 12 mo & 6.6 & $11.7^{*}$ \\
Nocturnal wheeze & & \\
$\quad$ Ever & 1.9 & $2.9^{*}$ \\
Last 12 mo & 0.6 & $1.4^{*}$ \\
Nocturnal cough & & $12.5^{*}$ \\
$\quad$ Ever & 6.9 & $7.1^{*}$ \\
Last 12 mo & 3.9 & \\
Severe wheeze & & $4.6^{*}$ \\
$\quad$ Ever & 3.4 & $2.6^{*}$ \\
$\quad$ Last 12 mo & 2.0 & \\
\hline
\end{tabular}

${ }^{*} P<0.05$, significant difference in the prevalence between 1995 and 2000 .

lence of current asthma symptoms and was also associated with decreased BMI. ${ }^{13}$ In addition, the occurrence of fever, antibiotic use, and an episode of acute gastroenteritis during infancy showed an association with development of asthma later in life. ${ }^{14}$ In multiple logistic regression analysis, increased BMI (aOR, 1.04, 95\% CI, 1.02-1.06), passive smoking (aOR, 1.54, 95\% CI, 1.31-1.81), and living with a dog or cat (aOR, 1.25, 95\% CI, 1.11-1.41) were risk factors that were associated with asthma in junior high school students. ${ }^{22}$ The results do not mean that these risk factors are the causes of childhood asthma, because our study was a cross-sectional questionnaire-based survey. Further investigations, such as a birth cohort study, are needed to elucidate the causal relationships.

\section{WORLD TIME TRENDS IN PREVALENCE OF CHILDHOOD ASTHMA}

Since ISAAC Phase One in 1995, Phase Two and Phase Three were developed to identify determinants of the observed differences in prevalence rates in different countries, and to investigate the time trends of prevalence. According to the ISAAC Phase One and Three multicountry cross-sectional surveys, ${ }^{18}$ the prevalence of asthma symptoms (wheezing in the past 12 months) in the 6-7 years age group increased in 25 centers out of 66 and decreased in 14, which shows that most children in this age group are still increasingly suffering from asthma. Twenty-seven centers showed little change. However, in Korean children aged 6-7 years, the prevalence of asthma symptoms was $13.3 \%$ in 1995 and decreased to $5.8 \%$ in 2000. In the 13-14 years age group, the prevalence of asthma symptoms changed in most centers (77\%). Of the 82 centers with changes, prevalence increased in 42 and decreased in 40. For lower mean prevalence values, more centers showed an increase in prevalence, but for centers with higher mean prevalence, a decrease in prevalence was more common. A similar trend was found in 13-14 years old children in Korea who showed an increase in prevalence from $7.7 \%$ to $8.7 \%$. When the annual change in prevalence was estimated, ${ }^{18,24}$ the prevalence of wheeze in the last 12 months in children aged 6-7 years increased from $11.1 \%$ to $11.6 \%$, with a change of $+0.13 \%$ per year. Western Europe, Latin America, North America, Africa, Northern/Eastern Europe showed positive annual changes in prevalence, although the annual change in the prevalence in Korean children in this age group was $-1.45 \%$ per year. In the $13-14$ years age group, it was found that Korea $(+0.20 \%$ per year) and many other countries showed consistent patterns, apart from Oceania ( $-0.39 \%$ per year) and English-speaking countries $(-0.51 \%$ per year). The exact reason for the different changes in prevalence in different geographical regions, including Korea, remains unclear, although different environmental factors might be involved in each region at a different time.

\section{CONCLUSIONS}

Based on the results from the nationwide epidemiological studies in 1995 and 2000, the prevalence of asthma symptoms in Korean children is not very high when compared with those of developed countries. The prevalence of asthma in junior high school children seems to have increased over the 5 years. However, in elementary school children, the prevalence of asthma symptoms decreased, although the prevalence of "diagnosis of asthma, ever" and "treatment of asthma, last 12 months" increased. In addition, it was found that various factors such as obesity, passive smoking, dietary habits, raising pets at home, and fever/antibiotic use during infancy are associated with childhood asthma.

Fifteen years have passed since the first survey, and it is time to conduct another epidemiological study to evaluate the trends over time. KAPARD has a plan to conduct a third nationwide survey in 2010, and we anticipate that ISAAC Phase 3 will explore recent changes in the prevalence of childhood asthma and assess its risk factors in Korean children. On the basis of accurate data on the current status of childhood asthma in 2010, we will be able to establish proper management strategies.

\section{ACKNOWLEDGMENTS}

We thank all of the members of KAPARD, and all participants in this survey for their invaluable assistance.

\section{REFERENCES}

1. Stewart AW, Mitchell EA, Pearce N, Strachan DP, Weiland SK. The relationship of per capita gross national product to the prevalence of symptoms of asthma and other atopic diseases in children 
(ISAAC). Int J Epidemiol 2001;30:173-9.

2. Strachan DP, Cook DG. Health effects of passive smoking. 6. Parental smoking and childhood asthma: longitudinal and case-control studies. Thorax 1998;53:204-12.

3. Nordling E, Berglind N, Melen E, Emenius G, Hallberg J, Nyberg F, Pershagen G, Svartengren M, Wickman M, Bellander T. Trafficrelated air pollution and childhood respiratory symptoms, function and allergies. Epidemiology 2008;19:401-8.

4. Hirshon JM, Shardell M, Alles S, Powell JL, Squibb K, Ondov J, Blaisdell CJ. Elevated ambient air zinc increases pediatric asthma morbidity. Environ Health Perspect 2008;116:826-31.

5. Ryan PH, Lemasters GK, Biswas P, Levin L, Hu S, Lindsey M, Bernstein DI, Lockey J, Villareal M, Khurana Hershey GK, Grinshpun SA. A comparison of proximity and land use regression traffic exposure models and wheezing in infants. Environ Health Perspect 2007;115:278-84.

6. Morgenstern V, Zutavern A, Cyrys J, Brockow I, Koletzko S, Kramer U, Behrendt H, Herbarth O, von Berg A, Bauer CP, Wichmann HE, Heinrich J. Atopic diseases, allergic sensitization, and exposure to traffic-related air pollution in children. Am J Respir Crit Care Med 2008;177:1331-7.

7. von Mutius E. Infection: friend or foe in the development of atopy and asthma? The epidemiological evidence. Eur Respir J 2001;18: 872-81.

8. Weiland SK, Husing A, Strachan DP, Rzehak P, Pearce N. Climate and the prevalence of symptoms of asthma, allergic rhinitis, and atopic eczema in children. Occup Environ Med 2004;61:609-15.

9. Weiland SK, von Mutius E, Husing A, Asher MI. Intake of trans fatty acids and prevalence of childhood asthma and allergies in Europe. ISAAC Steering Committee. Lancet 1999;353:2040-1.

10. Ellwood P, Asher MI, Bjorksten B, Burr M, Pearce N, Robertson CF. Diet and asthma, allergic rhinoconjunctivitis and atopic eczema symptom prevalence: an ecological analysis of the International Study of Asthma and Allergies in Childhood (ISAAC) data. ISAAC Phase One Study Group. Eur Respir J 2001;17:436-43.

11. Chinn S, Rona RJ. Can the increase in body mass index explain the rising trend in asthma in children? Thorax 2001;56:845-50.

12. Schaub B, von Mutius E. Obesity and asthma, what are the links? Curr Opin Allergy Clin Immunol 2005;5:185-93.

13. Hong SJ, Lee MS, Lee SY, Ahn KM, Oh JW, Kim KE, Lee JS, Lee HB. High body mass index and dietary pattern are associated with childhood asthma. Pediatr Pulmonol 2006;41:1118-24.

14. Ahn KM, Lee MS, Hong SJ, Lim DH, Ahn YM, Lee HR, Lee MI, Lee
MH, Shin YK, Kim KE. Fever, use of antibiotics, and acute gastroenteritis during infancy as risk factors for the development of asthma in Korean school-age children. J Asthma 2005;42:745-50.

15. Illi S, von Mutius E, Lau S, Niggemann B, Gruber C, Wahn U. Perennial allergen sensitisation early in life and chronic asthma in children: a birth cohort study. Lancet 2006;368:763-70.

16. Burr ML, Emberlin JC, Treu R, Cheng S, Pearce NE. Pollen counts in relation to the prevalence of allergic rhinoconjunctivitis, asthma and atopic eczema in the International Study of Asthma and Allergies in Childhood (ISAAC). Clin Exp Allergy 2003;33:1675-80.

17. Worldwide variation in prevalence of symptoms of asthma, allergic rhinoconjunctivitis, and atopic eczema: ISAAC. The International Study of Asthma and Allergies in Childhood (ISAAC) Steering Committee. Lancet 1998;351:1225-32.

18. Asher MI, Montefort S, Bjorksten B, Lai CK, Strachan DP, Weiland SK, Williams H. Worldwide time trends in the prevalence of symptoms of asthma, allergic rhinoconjunctivitis, and eczema in childhood: ISAAC Phases One and Three repeat multicountry cross-sectional surveys. Lancet 2006;368:733-43.

19. Eder W, Ege MJ, von Mutius E. The asthma epidemic. N Engl J Med 2006;355:2226-35.

20. Lee SI, Shin MH, Lee HB, Lee JS, Son BK, Koh YY, Kim KE, Ahn YO. Prevalences of symptoms of asthma and other allergic diseases in korean children: a nationwide questionnaire survey. J Korean Med Sci 2001;16:155-64.

21. Hong SJ, Kim SW, Oh JW, Rah YH, Ahn YM, Kim KE, Koh YY, Lee SI. The validity of the ISAAC written questionnaire and the ISAAC video questionnaire (AVQ 3.0) for predicting asthma associated with bronchial hyperreactivity in a group of 13-14 year old Korean schoolchildren. J Korean Med Sci 2003;18:48-52.

22. Hong SJ, Lee MS, Sohn MH, Shim JY, Han YS, Park KS, Ahn YM, Son BK, Lee HB. Self-reported prevalence and risk factors of asthma among Korean adolescents: 5-year follow-up study, 1995-2000. Clin Exp Allergy 2004;34:1556-62.

23. Hong SJ. Korean ISAAC Study Group of Korean Association of Allergy and Respiratory Diseases. Report of Korean ISAAC epidemiologic study for asthma and allergic diseases in children. Pediatr Allergy Respir Dis (Korea) 2007;17 Suppl 1:S55-66.

24. Pearce N, Ait-Khaled N, Beasley R, Mallol J, Keil U, Mitchell E, Robertson C. Worldwide trends in the prevalence of asthma symptoms: phase III of the International Study of Asthma and Allergies in Childhood (ISAAC). Thorax 2007;62:758-66. 